\title{
OS ESCRITOS POMBALINOS SOBRE A INGLATERRA E SUA RELAÇÃO COM O ENSINO DE INGLÊS EM PORTUGAL E NO BRASIL (1762-1809)
}

\author{
Luiz Eduardo Meneses de Oliveira*
}

\section{RESUMO}

Este artigo investiga o modo como os escritos de Pombal sobre a Inglaterra e sua experiência diplomática em Londres, entre 1738 e 1742, repercutiram em suas iniciativas referentes ao ensino, de modo geral, e ao ensino de inglês, de modo particular, quando se tornou ministro de D. José I, em Portugal, entre 1750 e 1777. Para tanto, faremos uso da historiografia, da legislação e de correspondências publicadas, bem como de gramáticas inglesas e dicionários do período.

Palavras-chave: história da educação, Marquês de Pombal, Inglaterra, ensino de inglês.

* Universidade Federal de Sergipe (UFS), Aracaju/SE, Brasil. 


\section{LAS ESCRITURAS POMBALINAS SOBRE INGLATERRA $Y$ SU RELACIÓN CON LA ENSEÑANZA DEL INGLÉS EN PORTUGAL Y BRASIL (1762-1809)}

\section{RESUMEN}

Este artículo investiga la forma de cómo las escrituras de Pombal sobre Inglaterra y su experiencia diplomática en Londres, entre 1738 y 1742, han repercutido en sus iniciativas sobre la enseñanza, en general, y sobre la enseñanza del inglês, en particular, cuando se convirtió en Ministro de D. José I, en Portugal, entre 1750 y 1777. Para ello, consultamos la historiografía, la legislación y las correspondencias publicadas, así como gramáticas inglesas y diccionarios de la época.

Palabras clave: historia de la educación, Marqués de Pombal, Inglaterra, enseñanza de inglés.

\section{THE POMBALINE WRITINGS ON ENGLAND AND ITS RELATION TO THE TEACHING OF ENGLISH IN PORTUGAL AND BRAZIL (1762-1809)}

\section{ABSTRACT}

This article investigates the way how the writings of Pombal on England and his experience as a diplomat in London between 1738 and 1742 reverberated in his political enterprises related to teaching, in general, and the teaching of English, in particular, when he became minister of D. José I, in Portugal, between 1750 and 1777. To reach these objectives, we will use the historiography, legislation, published epistolary sources and English grammars and dictionaries of the period.

Keywords: history of education, Marquis of Pombal, England, teaching of english.

\section{LES ÉCRITS POMBALINE SUR L'ANGLETERRE ET SA RELATION AVEC L'ENSEIGNEMENT DE L'ANGLAIS AU PORTUGAL ET AU BRÉSIL (1762-1809)}

\section{RÉSUMÉ}

Cet article recherche la manière dont les écrits de Pombal sur l'Angleterre et son expérience diplomatique à Londres, entre 1738 et 1742, ont eu des répercussions sur ses initiatives concernant l'enseignement, en general, et l'enseignement de l'anglais, en particulier, lorsqu'il est devenu ministre de D. José I, au Portugal, entre 1750 et 1777 . Pour cela, nous utiliserons l'historiographie, la législation et les correspondances publiées, ainsi que des grammaires et dictionnaires anglais de l'époque.

Mots-clés: histoire de l'éducation, Marquis de Pombal, Angleterre, enseignement de l'anglais. 


\section{INTRODUÇÃO}

O reinado de D. João V (1689-1750) foi marcado, dentre outras coisas, pelos efeitos do Tratado de Methuen (1703), tendo Portugal adquirido, em sua memória histórica, a imagem de um reino afastado tanto de seus vizinhos ibéricos - mesmo depois dos casamentos reais entre as duas Casas peninsulares - quanto da Europa ilustrada, sob a liderança de um rei tido por lúbrico e beato. ${ }^{1}$ Todavia, do ponto de vista cultural, o período joanino caracteriza-se pela importação de artistas e intelectuais estrangeiros, especialmente músicos italianos, bem como pela encomenda sistemática de pinturas e obras arquitetônicas, graças ao incremento financeiro advindo do ouro do Brasil. Assim, são do período joanino a construção do palácio e convento de Mafra, de 1713 a 1730, a fundação da Real Academia da História Portuguesa, que funcionou de 1720 a 1776, a tradução e impressão de obras portuguesas e estrangeiras, inclusive de periódicos, e a constituição da figura do homem de letras "estrangeirado" ${ }^{2}$, representado por escritores que tiveram experiências diplomáticas ou formativas internacionais, tais como D. Luís da Cunha, Alexandre de Gusmão (1695-1753), Martinho de Mendonça de Pina Proença (1693-1743), António Nunes Ribeiro Sanches (16991783), Luís António Verney (1713-1792) e Sebastião José de Carvalho e Melo (1699-1782), mais tarde Marquês de Pombal.

A estrutura social de Portugal, nesse período, é característica das formações sociais ibéricas do século XVIII, sendo constituída pelo clero, seu

\footnotetext{
${ }^{1}$ Voltaire (1694-1778), por exemplo, assim descrevia o monarca português: "Quando queria uma festa, ordenava um desfile religioso. Quando queria uma construção nova, erigia um convento. Quando queria uma amante, arrumava uma freira" (apud MAXWELL, 1996, p. 17). Esta é a visão, também, de alguns viajantes que passaram por Portugal no século XVIII, como Richard Twiss (1775).

2 Para Francisco J. C. Falcon (1993, p. 204; 320), “o fenômeno do 'estrangeiramento' pode ser definido como "o produto de uma cisão entre aqueles que, viajando e que vinham de fora, militares e diplomatas de outras nações, puderam mudar suas maneiras de ver e de sentir, e os demais que, insulados, ficaram impermeáveis a tudo que viesse do estrangeiro. Foi este o ponto de partida para a divisão ideológica entre os nacionais ou 'castiços' e os 'estrangeiros', questão magna da Ilustração portuguesa [...]”. Desse modo, os estrangeirados podem sê-lo pelo sangue ou pela educação: "O sangue é hebraico, é o que une os judeus e cristãos-novos, separando-os dos castiços. A educação é a cultura absorvida no exterior, desnacionalizante, contrária à formação castiça”.
} 
primeiro "braço", pela nobreza e pelo "terceiro estado", onde se agrupavam várias gradações dos setores rural e urbano. Vale ressaltar, em tal contexto, o crescimento das cidades, que passam a ser povoadas por oficiais mecânicos e empregados de oficinas, do comércio e de serviços domésticos, bem como por desocupados, mendigos, negros, ciganos e escravos, e o aumento dos funcionários públicos, o que favorece à burguesia - comerciantes e empresários manufatureiros - na competição pelos novos cargos criados pelo governo, em detrimento dos nobres e membros do clero (FALCON, 1993, p. 181-183).

O "homem de letras", em muitos aspectos, assemelha-se à figura do "intelectual". Em texto clássico sobre os intelectuais e a organização da cultura, Gramsci $(2006$, p. 15; 18) afirma que, embora seja possível dizer que todos os homens são intelectuais, independentemente do tipo de atividade que desenvolvem, apenas alguns têm essa função na sociedade, pois todo grupo social cria para si, organicamente, uma ou mais camadas de intelectuais que lhe dão homogeneidade e consciência de sua própria função, nos campos econômico, social e político. Bauman (2010, p. 15), por sua vez, esclarece que, na época em que foi cunhada - nos primeiros anos do século XX -, a palavra "intelectual" buscou recapturar e reafirmar a centralidade social e as preocupações globais em voga no Iluminismo, pois era aplicada indistintamente a uma série de romancistas, poetas, artistas, jornalistas, cientistas e outras figuras públicas que exerceram influência sobre as mentalidades da nação. Com efeito, a Encyclopédie, ao redefinir o mundo do conhecimento para os leitores modernos, identificou-o com os philosophes, de modo que a emergência de tais "homens de letras" como novo tipo social, e com força suficiente para interferir nos rumos políticos e culturais de determinadas formações sociais, coincide com as publicações e episódios históricos associados ao que se concebe como Iluminismo. Nesse sentido, o que hoje identificamos como intelectual corresponde, em parte, ao philosophe, ou homem de letras do século XVIII (DARNTON, 2005, p. 24-25).

No caso de Portugal, Falcon (1993, p. 229) identifica três tipos de 
intelectuais nesse período: os "intelectuais tradicionais eclesiásticos", que representam a antiga ordem senhorial; os "intelectuais tradicionais nãoeclesiásticos", que são os integrantes do aparelho burocrático do Estado absolutista - juízes, conselheiros, diplomatas, administradores etc. -, e os "novos intelectuais", que, embora fossem egressos dos tipos anteriores, são orgânicos em relação à burguesia em ascensão, constituindo, no século XVIII, o tipo consagrado do "homem de letras". Nesse sentido, o período joanino pode ser entendido como um momento de transição, uma vez que precede a viragem política e ideológica da época pombalina. É um período de riqueza, ostentação e luxo, visível no esplendor barroco de sua arquitetura e carruagens, vestimentas, procissões, autos-de-fé e festas populares, tudo patrocinado pelo fluxo aurífero. É também “a época de ouro dos freiráticos", caracterizada pelo assédio dos nobres aos conventos, onde se achavam moças de famílias renomadas que não encontravam casamento e para lá eram mandadas por imposição paterna. Para Saraiva e Lopes (2008, p. 595), o reinado de D. João V caracteriza-se por uma contradição fundamental: se, por um lado, o surto da mineração brasileira proporciona a ocasião ideal para o realinhamento da aristocracia e do clero ao trono absolutista, possibilitando assim o florescimento da cultura barroca, por outro o aparente isolamento de Portugal com relação à Europa começa a ser objeto de críticas dos estrangeirados, algo que vai servir de mote ao discurso da legislação pombalina, que busca colocar Portugal em condições de igualdade com as "nações polidas da Europa".

É justamente sobre a defasagem cultural, política e econômica de Portugal com relação às demais potências da Europa que vai recair a crítica dos estrangeirados. O fluxo aurífero e diamantino fazia aflorar problemas monetários que colocavam em primeiro plano as questões econômicas, as quais encontravam expressão num discurso mercantilista de que são precursores, dentre outros, o padre Antônio Vieira (1608-1697) e Duarte Ribeiro de Macedo (1618-1680). Tais discursos encontraram expressão política em D. Luís de Meneses (1632-1690), terceiro conde de Ericeira, vedor da Fazenda que, a partir de 1675, passou a impulsionar a manufatura, tendo em vista o problema da balança comercial, mas 
irão consolidar-se somente com os intelectuais estrangeirados da geração seguinte, os quais, tendo a vantagem de observar a situação de outros países europeus, voltavam seu olhar distanciado para a situação de isolamento e decadência de Portugal, no intuito de diagnosticar as suas causas.

Não por acaso, nos discursos político-econômicos pré-pombalinos, isto é, nos estudos produzidos pelos homens de letras do reinado de D. João V, como Alexandre de Gusmão (1695-1753), D. Luís da Cunha (1662-1749) e Sebastião José de Carvalho e Melo (1699-1782), destaca-se o caráter destrutivo que é atribuído à aliança inglesa, que havia sujeitado a nação portuguesa à humilhação de ter que depender da Inglaterra até mesmo para os cereais necessários à sua subsistência. Segundo Maxwell (2005, p. 25), na primeira metade do século XVIII, apenas a Holanda e a Alemanha sobrepujavam Portugal como consumidores das exportações inglesas, e somente nos momentos mais críticos da Guerra dos Sete Anos (1756-1763) os navios britânicos no porto de Lisboa ficaram aquém de cinquenta por cento do total. Azevedo (2004, p. 220) chega a afirmar que, depois do Tratado de Methuen, Portugal, como principal consumidor das manufaturas inglesas, era "a mais excelente colônia da GrãBretanha”. Seu comércio era praticamente monopolizado pelos súditos ingleses, que vinham fazer fortuna no Porto ou em Lisboa, mas também trabalhar como tanoeiros, sapateiros, alfaiates e cabeleireiros, de modo que a imigração abarcava todo tipo de gente, desde o "inglês falido" ao irlandês fugido da forca de Londres.

Os principais argumentos do Testamento Político de D. Luís da Cunha, bem como dos Apontamentos Históricos, Políticos e Cronológicos sobre as fábricas do Reino, de Alexandre de Gusmão, foram reaproveitados, desenvolvidos e até aplicados por Sebastião José de Carvalho e Melo, que, vindo de uma modesta família de pequenos fidalgos que serviram como soldados, sacerdotes e funcionários públicos, por intermédio do seu primo, Marco Antônio de Azevedo Coutinho (1688-1750), tornou-se diplomata em Londres (1738-1744) e em Viena (1745-1749), chegando a Secretário dos Negócios Estrangeiros e da Guerra com a ascensão de D. José I (1714-1777) ao trono português, e Secretário 
dos Negócios do Reino em 1755, quando exerceu controle quase absoluto dos assuntos relativos ao governo. Em 1759, recebeu o título de Conde de Oeiras e em 1769 o de Marquês de Pombal, como ficou conhecido na história portuguesa. De acordo com Maxwell (1996), Pombal, para todos os efeitos, governou Portugal entre 1750 e 1777. Sua autoridade consolidou-se depois do terremoto de Lisboa, em 1755, quando assumiu o projeto de reconstrução da cidade, dando-lhe uma nova arquitetura, e da restauração da ordem, com uma política autoritária, rígida e radical em seus objetivos.

\section{OS ESCRITOS LONDRINOS}

Conforme a classificação proposta por Falcon (1993, p. 280-285), o primeiro grupo de escritos pombalinos, composto dos escritos sobre as relações econômicas anglo-lusitanas, compreende o período que vai de 1738, ano de sua chegada a Londres como diplomata, ainda durante o reinado de D. João V, até 1778, quando o Marquês, depois da morte de D. José I e de sua queda do ministério, se defendia dos seus adversários políticos.

Assim, os primeiros textos desse primeiro grupo foram produzidos durante o tempo que Sebastião José de Carvalho e Melo passou em Londres como diplomata, de 1738 a 1742. Em 8 de outubro de 1738, ele partiu para a Inglaterra, a bordo do navio britânico King of Portugal, como novo enviado extraordinário de Portugal à corte de Jorge II (1683-1760), por indicação de D. Nuno, o cardeal da Cunha (1664-1750), para substituir seu primo Marco Antônio de Azevedo Coutinho, que, estando em Londres desde 1735, voltou ao reino português, a pedido de D. João V, para exercer o cargo de Secretário de Estado, morrendo logo depois.

A primeira missão de Carvalho e Melo era pedir auxílio militar ao governo inglês para defender as possessões portuguesas na Índia, ameaçadas pelos maratas, que haviam tomado a ilha de Salsete, e pelos bonsulós, que assediavam 
Goa. O gabinete britânico, chefiado à época por Robert Walpole (1676-1745), assim como na ocasião dos ataques espanhóis na fronteira da colônia de Sacramento, mesmo sem se negar ao cumprimento do Tratado da Liga Defensiva de 1703, usava de vários subterfúgios para se eximir de tal responsabilidade, alegando que não poderia fazer nada sem ouvir a Companhia das Índias Orientais - fundada em 1698 por Guilherme III (1650-1702) -, que, por sua vez, tinha muito interesse na derrota dos portugueses, como veio provar a sua posterior anexação da ilha de Salsete ao seu império, bem como de outras praças portuguesas vizinhas a Bombaim. O problema foi resolvido com o envio de uma esquadra portuguesa, em 1740, na qual estava D. Luís Carlos Xavier de Meneses (1689-1742), quinto conde de Ericeira, que assumiu, pela segunda vez, o cargo de vice-rei da Índia. No entanto, o conflito deixou vários soldados portugueses mortos, entre eles José Joaquim de Carvalho (c. 1712-1740), irmão mais novo de Pombal (MELO apud BARRETO, 1986, p. vii; xii-xiii).

Sebastião José retornou a Portugal em 1743, sob a alegação de problemas de saúde, e em dezembro de 1744 partiu novamente para Londres, onde permaneceu durante seis meses, antes de seguir para a Áustria, espécie de exílio a que foi submetido por circunstâncias políticas e onde permaneceu como diplomata até 1749, casando-se, pela segunda vez, com D. Leonor Daun (17091789), filha do famoso general conde Von Daun (1669-1741), que se destacou na Guerra de Sucessão Espanhola, e dama da corte da rainha Maria Teresa (17171780). Nesse sentido, sua missão na Inglaterra, se foi nula ou estéril, como sugere certa historiografia, teve que enfrentar todas as dificuldades impostas pelas circunstâncias históricas do momento.

Seus escritos dessa época, que, pela sua extensão, enfastiavam tanto D. João V quando o duque de Newcastle3, longe de se filiarem ao grupo de escritos genérica e pejorativamente chamados de "estrangeirados" buscavam explicar as

\footnotetext{
3 Conforme Azevedo (1991, p. 45-46), seus despachos, além de serem longos, eram emaranhados e prolixos, tendo o diplomata, por conta disso, ganhado o irônico apelido de "ministro letrado", pela grande quantidade de citações e abuso de fórmulas de jurisprudência, o que tornava seu estilo pedante e confuso.
} 
causas profundas do estado de decadência do comércio e da economia portuguesa, que é sempre contraposto ao desenvolvimento da Inglaterra e de outras "nações polidas da Europa", através de uma comparação em negativo na qual o outro, como um espelho invertido, aparece como modelo a ser imitado. Sua primeira oportunidade de expor suas ideias sobre as relações políticodiplomáticas luso-britânicas ocorreu depois que recebeu de Lisboa, em 15 de outubro de 1740, um ofício com a contraproposta portuguesa ao projeto de convenção inglês contra a Espanha. No ofício, exigia-se a reparação das negligências ou contravenções do Artigo XV do Tratado de Aliança Defensiva de 16 de maio de 1703 e do Artigo Secreto do Tratado de Paz de 10 de julho de 1654, que garantiam aos portugueses na Inglaterra a reciprocidade de privilégios e liberdades do comércio que os ingleses tinham em Portugal. Ao representante do governo português em Londres cabia instruir-se a respeito da questão, antes de emitir seu parecer, o que fez no mesmo ano, ao interromper as negociações e começar a redigir uma relação dos gravames que ao Comércio e Vassalos de Portugal se tem inferido e estão atualmente inferindo por Inglaterra com as infrações que dos pactos recíprocos se tem feito por este Segundo Reino; assim nos Atos do Parlamento que publicou, como nos costumes que estabeleceu; e nos outros diversos meios de que se serviu para fraudar os Tratados do Comércio entre as Duas Nações.

Antes de escrever a Relação dos gravames, que só foi enviada a Lisboa no dia 2 de março de 1741, o diplomata havia redigido uma longa Carta de Ofício, datada de 2 de janeiro de 1741 e dirigida a Marco Antônio de Azevedo Coutinho, sobre a questão. Ao contrário de Alexandre de Gusmão, que chegou a propor a anulação dos tratados com a Inglaterra em proveito de uma aliança com a França, o enviado português defendia a manutenção da aliança inglesa, pois, em seu entender, não era o Tratado de Methuen a principal causa da ruína da economia portuguesa, mas a sua infração pela ambição, cobiça e soberba dos ingleses, que invejavam o "nosso Brasil" e eram considerados como os "tiranos do comércio" (MELO, 1986, p. 7). 
Apesar de inacabada, a Relação dos gravames é bem estruturada e apresenta suas teses econômicas de forma sistematizada. Após expor os "Motivos da obra”, que se justificam pela importância da regulamentação do comércio para qualquer nação, o autor faz um "Juizo geral do comercio de ambos os reynos", no qual, com base na análise dos tratados firmados entre os dois países, busca mostrar como Portugal sustenta todo o peso das convenções, que se tornaram muito onerosas, enquanto a Inglaterra, tendo pouco ou nenhum encargo, recolhe delas todo o proveito. Sobressai, no conjunto de textos, a imagem negativa com que são representados os ingleses, pela sua cobiça e prepotência. Assim, buscando descrever os "humores que formão o carácter dos que habitam e os costumes que nelle se observão como regras, que são inalteraveis" (MELO, 1986, p. 52), o enviado português afirma que, apesar de os britânicos não serem sanguinários, eram saqueadores das fazendas alheias, o que se justificava pela sua pretensão de assenhorear-se do mundo. Em seguida considera os ingleses de todos os grupos sociais como membros de um complot, ou conspiração para arruinar e destruir todos os estrangeiros que se opusessem aos seus interesses. Apesar do seu tom ao mesmo tempo caricatural e rancoroso, que em alguns aspectos chega a ser exagerado, o texto não deixa de documentar a experiência de um diplomata que representa um país frágil e dependente na capital do reino que vivia um momento de cristalização das ideias e mitologias expansionistas e imperiais.

Têm uma importância inquestionável na história do pensamento econômico português suas correspondências oficiais - na condição de diplomata - e particulares, que abordam dois temas importantes para o contexto da época. O primeiro é o receio de que a cobiça e a falta de escrúpulos dos ingleses os levassem a ocupar Buenos Aires, ganhando os portugueses na América perigosos “vizinhos de portas a dentro", daí a sua rejeição da oferta de auxílio militar da Inglaterra no conflito com a Espanha sobre a colônia de Sacramento. O segundo é a presença universal dos judeus, que, com seus cabedais, desempenhavam a função de banqueiros, comerciantes, advogados e médicos em países como a Inglaterra e a Holanda, para onde levavam seus cabedais. Sua preocupação era 
de que, havendo muitos cristãos-novos no Brasil e nas colônias espanholas, eles provavelmente apoiariam os ingleses, tanto por suas relações familiares e pessoais em Londres quanto pelo ressentimento de terem sido expulsos de seu país de origem, o que o levaria, já como ministro de D. José I, a referir-se às manobras de um monopólio internacional anglo-judaico.

\section{DA REPULSA À ADMIRAÇÃO: O CASO DA AULA DO COMÉRCIO}

Apesar de mitificar a Inglaterra como encarnação de um mal à economia e à prosperidade portuguesas, Carvalho e Melo, em seus escritos produzidos durante o tempo em que esteve diplomata em Londres, manifesta um certo fascínio pelo desenvolvimento comercial e marítimo dos ingleses, assim como pela simplicidade, flexibilidade e eficácia do seu sistema de manufaturas. Tal fascínio, no entanto, não impedia que o diplomata português criticasse asperamente o sistema político inglês, dado o conflito de prerrogativas entre a coroa e o parlamento, bem como a preponderância dos interesses pessoais sobre os da nação. Com a morte de D. João $\mathrm{V}$ e a ascensão de D. José I ao trono português, ele se torna Secretário dos Negócios Estrangeiros e da Guerra, o que lhe vai possibilitar pôr em prática muitas das convicções adquiridas em sua experiência diplomática, expedindo uma série de medidas tendentes à proteção do comércio e da economia portuguesas, em oposição ao que considerava "usurpações" dos tratados firmados com a Inglaterra. No entanto, tais medidas, em muitos casos, eram sub-reptícias e até mesmo veladas, dada a importância, por ele reconhecida, da manutenção da aliança inglesa, perante as constantes ameaças espanholas aos domínios portugueses na América, o que não o impedia de sugerir aos aliados, sempre que podia, a possibilidade de uma aliança com a França, como um meio de barganha em suas negociações políticas e diplomáticas (MELO, 1984).

Na primeira fase de sua governação, ocorreram acontecimentos decisivos 
para o desdobramento das relações político-diplomáticas entre Portugal e Inglaterra: a implementação do Tratado de Madri (1750), o terremoto de Lisboa, em 1755, e a Guerra dos Sete Anos (1756-1763), que opôs a França, a Rússia e a Áustria à Prússia e à Inglaterra. A Espanha, inicialmente neutra no conflito, aliouse à França em 1759, quando da subida ao trono de Carlos III (1716-1788), após a morte de Fernando VI (1713-1759), sobretudo quando os ingleses começaram a atacar, no final de 1760, as colônias espanholas das Antilhas. A diplomacia portuguesa tentou, sem sucesso, casar o rei viúvo da Espanha e seu primogênito com infantas portuguesas, mas em 1761, com a formação do terceiro Pacto de Família entre os monarcas da Casa de Bourbon da França, da Espanha, de Nápoles e Parma, a França exigiu que Portugal fechasse os portos aos ingleses. Mantida a já histórica aliança inglesa, sacramentada que estava pelo Tratado de Methuen, os exércitos franceses e espanhóis atacaram Portugal em abril de 1762, declarando guerra posteriormente. Foi nesse período também que começou a manifestar-se de modo mais ostensivo o descontentamento dos setores mercantis ingleses com relação às medidas protecionistas de Pombal, e a tornarem-se evidentes manobras de açambarcamento de trigo realizadas por comerciantes ingleses, burlando assim o Regimento do Terreiro do Trigo (AZEVEDO, 2004).

Sobre este último episódio, há um documento atribuído ao ministro de D. José I, e datado de 1753, intitulado Compêndio histórico do que tem passado em Lisboa sobre a insistência de alguns negociantes ingleses e holandeses que de acordo com outros portugueses pretenderam em diferentes ocasiões fazer na mesma cidade um violento monopólio do Pão. Um ano antes, o novo ministro havia escrito uma Instrução para "D. Luís da Cunha que partiu para Londres e suas Memórias secretíssimas para o Ministério de Londres. As Memórias secretíssimas", da mesma forma, insistiam no fato de que o enviado deveria persuadir os ingleses de que Portugal desejava conservar a amizade e aliança sacramentada pelos tratados de 1703, dados os interesses políticos e econômicos recíprocos, mas a intenção do ministro é alertar o enviado português das intrigas fomentadas pelo governo inglês, que buscava colocar Portugal contra a Espanha no intuito de mantê-lo dependente da Inglaterra, mal que enfermava o país 
(MELO, 1984).

Dada a importância, à época, do desenvolvimento do comércio para a prosperidade econômica de Portugal, o ministro de D. José I havia não somente legislado sobre questões consideradas emergenciais, como as referentes ao negócio do vinho e das matérias primas produzidas no Brasil, mas também sobre a formação de futuros comerciantes, o que só traria resultados a longo prazo. Assim, antes da reforma dos Estudos Menores, em 1759, Pombal buscou desenvolver, no campo da Instrução Pública, os setores relacionados com as tentativas de recuperação econômica da nação portuguesa, que, embora possuísse uma história de conquistas e riquezas, estava em decadência, sobretudo na América do Sul, onde a sangria, supostamente causada pelos jesuítas, negociantes ingleses, colonos, escravos libertos bem-sucedidos e contrabandistas, impedia um melhor aproveitamento do ouro e dos diamantes da colônia. Com esse argumento foi criada, pela Junta do Comércio, a Aula do Comércio, cujos estatutos foram publicados com o Alvará de 19 de maio de 1759, em razão da falta de formalidade na distribuição e ordem dos Livros do Comércio, tida como uma das causas da decadência de muitos negociantes, bem como da ignorância da redução dos dinheiros, pesos e medidas, câmbios e outras matérias mercantis, o que causava grandes prejuízos a Portugal, sobretudo em suas negociações com as nações estrangeiras. Com os mesmos objetivos foi criada, pela Junta Administrativa da Companhia Geral da Agricultura das Vinhas do Alto Douro, uma Aula de Náutica, com o Decreto de 30 de julho de 1762 (PORTUGAL, 1830).

Um ponto recorrente no discurso da legislação pombalina relativo à instrução comercial diz respeito à necessidade de tornar esta profissão digna para os nobres e a nascente burguesia mercantil, deixando de relacionar-se, no imaginário popular, com as atividades plebeias. O governo português, nesse sentido, buscava formar um novo homem, apto a enfrentar os desafios que a modernidade impunha ao comércio: o "perfeito negociante". Com efeito, já em 19 de fevereiro de 1742, na carta endereçada ao Cardeal da Mota, Carvalho e Melo, 
ao tratar do projeto de criação de uma companhia oriental, nos moldes da que tinham os ingleses, fazia ver que as atividades mercantis, na Inglaterra, eram reputadas como nobres, não somente pelo seu gênio, religião e costume, que não consideravam o enriquecimento terreno pecaminoso ou indecente, mas também pela importância com que tais atividades eram tidas para o progresso e prosperidade da nação (MELO, 1986, p. 134-135).

Por mais que suas iniciativas tenham encontrado obstáculos políticos e econômicos, o que fez com que muitas vezes não saíssem do papel, o fato é que elas iniciaram um movimento sem precedentes de valorização e institucionalização das atividades comerciais em Portugal. Em 29 de julho de 1803, por exemplo, foi publicado um Alvará confirmando os Estatutos da recémcriada Academia Real de Marinha e Comércio da Cidade do Porto, assinados por Luís Pinto de Sousa Coutinho (1735-1804), que previam o ensino de "hum systema de Doutrinas Mathematicas, e Navegação, e huma Aula de Commercio, outra de Desenho, e duas das Linguas Ingleza e Franceza", acrescentando "outra Aula para as lições de hum Curso de Filosofia Racional e Moral, assim como outra de agricultura" (PORTUGAL, 1826, p. 232).

A condição de ingresso para os discípulos, além da idade mínima de quatorze anos, era o conhecimento das quatro operações da Aritmética. As aulas das línguas francesa e inglesa são tratadas especificamente do Título XXIX ao XLIII, sendo possível verificar não apenas o seu papel como instrumento de acesso, pela tradução, aos conhecimentos adequados às matérias da academia, mas também um pouco do seu método de ensino, baseado principalmente na gramática e na tradução, com alguma ênfase na pronúncia, no intuito de apreender o "gênio", o "caráter", o "estilo" e "gosto" de cada uma delas nos "Authores dignos de se estudarem" (PORTUGAL, 1826, p. 239).

A Academia Real de Marinha e Comércio da cidade do Porto era uma reivindicação antiga da Junta Administrativa da Companhia Geral da Agricultura das Vinhas do Alto D'ouro, que em 1785 havia solicitado a El Rei a criação de Aulas de Matemática e Comércio. Sua Relação de 4 de janeiro de 1803, ao reforçar 
os argumentos em prol da criação da academia, é bastante esclarecedora a respeito da necessidade e utilidade do conhecimento das línguas estrangeiras para os marinheiros e comerciantes:

Que sendo o commercio desta cidade o mais consideravel do Reino, depois do da capital, e não se achando nella estabelecida aula de commercio, em que as pessoas, que se destinam a esta profissão possam adquirir os conhecimentos elementares do mesmo commercio: para o poderem exercer com perfeição e vantagem do Estado, se faz por isso muito necessario o estabelecimento da dita aula em utilidade publica: E que como muitas obras, que se acham escriptas, e se vão escrevendo em mathematica, em commercio, em agricultura, em fabricas e em navegação, é no idioma francez e inglez, e a maior navegação que fazem os navios deste porto, á exceção do Brazil, se destina para os paizes do Norte, e hoje felizmente para o Mar Baltico, nos quais é preciso saberem os mariantes as linguas vivas da Europa, principalmente as duas sobreditas franceza e ingleza, precisando tambem os commerciantes daquelle auxilio para melhor exercitarem a sua profissão na correspondencia do seu commercio, seria muito util o estabelecimento de uma aula de cada huma das referidas linguas; sendo esperavel, que da creação de todas as sobreditas quatro novas aulas nesta cidade, resultarão a este Reino de V. ${ }^{a} \mathrm{R}$. immensas utilidades, sendo ella tão populosa, e de habitantes tão industriosos e susceptíveis de toda a educação, do mesmo modo, que o são os desta provincia e das adjacentes (apud RIBEIRO, 1872, p. 401-402).

Não foi à toa que, assim que o Príncipe Regente chegou ao Brasil, uma de suas primeiras iniciativas foi abrir os portos às "nações amigas" - leia-se Inglaterra - e criar uma Aula Militar, para o que baixou um decreto nomeando um professor de francês e um de inglês (PORTUGAL, 1830). Já em seus Escritos Econômicos de Londres (1741-1742), Pombal, ao relatar as desvantagens enfrentadas por Portugal na controversa relação comercial mantida com a Inglaterra, afirmava que uma delas consistia no prejuízo decorrente das dificuldades durante o carregamento dos navios portugueses sem o acompanhamento devido de quem correspondesse, isto é, interpretasse os diálogos entre portugueses e ingleses. 
44. Para carregarem os navios portuguezes para a generalidade de nossos mercadores, seria necessário haver aqui outro igual ou grande número de correspondentes que os comunicassem, assim como é a mesma proporção que os mercadores de Inglaterra para sustentar entre nós o comércio necessitão de grande número de commissarios, que estableceram por todo o Portugal e Ilhas adjacentes. Não basta que haja em Portugal quem faça encomendas; he necessario que respectivamente haja em Inglaterra quem as avie e informe dos interesses e oportunidades para ellas primeiro se pedirem e depois se despacharem. Estes commissarios poes, no grande número em que são precisos ao nosso comercio, ou devem ser portugueses aqui estabelecidos ou os mesmos ingleses e gente do pays. 45. Se hão de ser portugueses, obsta-lhes: $1^{\circ}$ Não ter o nosso povo em aprender a lingoa inglesa o mesmo cuidado que tem os Inglezes em aprender a nossa para fazerem o comercio em Portugal, nas Ilhas e nas costas da India Oriental. Donde já por este impedimento da lingoa não pode aqui vir estabelecerse o numero de portugueses que era necessário [...] Resulta de tudo que ou em Portugal ha de haver escolas da lingoa ingleza e em Inglaterra cessar a infracção dos tratados que nos priva do estabelecimento, ou não pode aqui haver commissarios portuguezes difundidos e domiciliados como era precizo (MELO, 1986, p. 57-58) [grifos nossos].

\section{A INSTRUÇÃO COMERCIAL E O ENSINO DE INGLÊS}

As relações comerciais entre Portugal e Inglaterra acabaram por provocar o incremento do ensino do inglês e do português como língua estrangeira, inicialmente em Portugal e depois também em seus domínios. Esse era um discurso frequente nos prefácios das gramáticas e dicionários então publicados, desde A Portuguez Grammar, de 1662, escrita por um capitão francês chamado Monsieur de La Molliere e dedicada a Carlos II (1630-1685) da Inglaterra, logo depois de seu casamento com Catarina de Bragança (1638-1705), passando por $A$ Complete Account of the Portugueze Language, dicionário publicado em Londres em 1701 e composto por um certo A. J. - Alexander Justice, segundo Torre (1996, p. 33-47) -, até a Grammatica anglo-lusitanica \& lusitano-anglica, cuja primeira edição data de 1731, de autoria de Jacob Castro (TORRE, 1985).

Com efeito, o objetivo principal da primeira gramática inglesa escrita em 
português de que se tem notícia, conforme as palavras do autor no prefácio, era o seu great Use in Commerce, isto é, sua grande utilidade no comércio. Na edição a que tivemos acesso - a terceira, datada de 1759 e impressa em Londres -, o título completo é Grammatica anglo-lusitanica \& lusitano-anglica ou Gramatica Nova, Ingleza e Portugueza, e Portugueza e Ingleza; dividida em duas partes, a primeira para a "instruição dos Inglezes que desejarem alcançar o conhecimento da Lingua Portugueza" e a segunda "para o uso dos Portuguezes que tiverem a mesma inclinação a Lingua Ingleza”. Segundo informações da folha de rosto do livro, a primeira parte foi corrigida e emendada, e a segunda "executada por Methodo claro, familiar, e facil". O autor, J. Castro4, era "Mestre e Traductor de ambas as Linguas" e ensinava, tanto em sua casa quanto "por fora", a "Ler, Escrever, Contar, e Livro de Caixa pello Modo Italiano e em pouco Tempo (sem as costumadas Regras, Taboadas, e impertinentes ou inutils Questoens) por um Methodo, claro, patente, e bem a provado no estilo Mercantil", tendo já publicado um Tratado intitulado Hum presente para os mancebos em entrando ao Contor (Compting-House), como faz questão de frisar, numa "Advertência" escrita nas duas línguas (CASTRO, 1759, p. xii).

Em 1768, Antônio Vieira Transtagano (1712-1797) publicou em Londres A New Portuguese Grammar, cujos diálogos familiares foram várias vezes transcritos pelas gramáticas inglesas do século XIX. Do mesmo autor foi publicado, em 1773, A Dictionary of the Portuguese and English Language in two parts, em cujo prefácio afirmava que a língua inglesa era necessária a todas as nações que com a Inglaterra negociavam (TORRE, 1988, p. 5-9). Da mesma forma, Grammatica da Lingua Ingleza, ou A Arte de Fallar com Propriedade e

\footnotetext{
4 Segundo Cardim (2012, p. 106), o autor desta Gramática não deve ser confundido com o médico Jacob de Castro Sarmento (1691-1762), português de origem judaica residente em Londres: "Em primeiro lugar é inadmissível que o médico Jacob de Castro Sarmento, membro do Colégio real dos médicos e da Real Sociedade de Londres, autor de várias obras notáveis e privando com sábios fôsse em 1751 [ano da primeira edição da obra] 'mestre e traductor de ambas as linguas', como se lê no frontispício logo por baixo do nome J. Castro". Este, por sua vez, seria o autor somente da segunda parte da obra, sendo a primeira uma reedição da Epítome gramaticae lusitano-anglica, gramática anônima impressa em Londres em 1731, "largamente baseada na Ars gramaticae de Bento Pereira”.
} 
Correção o Idioma Inglez, publicada pela primeira vez em 1779 e escrita por Agostinho Neri da Silva, oficial da Secretaria de Estado dos Negócios Estrangeiros e Cônsul Geral de Portugal na Dinamarca, enfatizava a importância da língua inglesa para os portugueses por conta das relações comerciais anglo-portuguesas. Um ano depois, Diogo Inácio de Pina Manique (1733-1805), Intendente-Geral da Polícia desde 1760, quando foi instituído o órgão, criou a Casa Pia, em cujo Colégio de S. Lucas o inglês figurava entre as matérias de ensino. Caso diferente foi o de André Jacob, maçom de origem inglesa radicado em Lisboa, que enfatizava, para além de sua importância comercial, o caráter filosófico, científico e literário da língua inglesa, em sua Grammatica Portugueza, e Ingleza, publicada em Lisboa em 1793, na qual afirma que o inglês era a língua da filosofia, dos Bacons, Newtons, Lockes, Popes e Miltons, sendo, portanto, a língua que era recomendada pelos philosophes para todas as nações de espírito nobre. Segundo Cardim (2012, p. 107), esta gramática é simplesmente a tradução da "Prosodial Grammar com que abre o Dicionário de Sheridan".5

\section{A INSTRUÇÃO MILITAR E O ENSINO DE INGLÊS}

Já no início da década de 1760 os ingleses haviam percebido o verdadeiro objetivo da legislação econômica de Pombal, o que se nota tanto pela correspondência trocada com o diplomata português em Londres Martinho de Melo e Castro (1716-1795) quanto pelos relatórios do representante do governo inglês em Lisboa, Mr. Hay, nos quais informava, dentre outras coisas, que a meta de Pombal era estabelecer um comércio ativo entre os indivíduos de Portugal e

\footnotetext{
5 Trata-se de Thomas Sheridan (1719-1788) - pai do dramaturgo Richard Brinsley Sheridan (17511816) -, cujo Dictionary of the English language foi publicado em 1780. Com suas Lectures on elocution (1762) e Lectures on reading (1775), Sheridan, também um homem de teatro, foi uma das principais personagens no movimento inglês de promoção do "bem falar" (good speech) na segunda metade do século XVIII, tornando-se famoso professor de elocução entre os cavalheiros e damas da corte, em um momento no qual a ortografia e a fonética da língua inglesa já se achavam fixadas pelos mais importantes gramáticos do século anterior, como John Wallis (16161703) e Christopher Cooper (1646-1698), cuja Gammatica linguae anglicanae saiu em 1685 (HOWATT, 1988, p. 76).
} 
tornar inúteis os agentes estrangeiros. Assim, não é de surpreender que, ao requerer o auxílio militar britânico, em 1762, o ministro tenha tomado o cuidado de não fazer referências aos tratados anglo-portugueses, privando assim os franceses e espanhóis do argumento que tinham usado para invadir Portugal, de que aqueles tratados eram ofensivos, e não defensivos. Como à Inglaterra não interessava que Lisboa ficasse em mãos inimigas, seus pedidos foram atendidos. Para o comando das tropas inglesas nessa expedição Pombal indicou o nome de Lord Tyrawly, que teve muitos filhos ilegítimos nascidos em Portugal e havia se mostrado simpático com relação à sua política em 1752, mas que agora já estava muito velho para o bom desempenho de suas funções, motivo pelo qual foi substituído por Wilhelm Graf von Schaumburg-Lippe (1724-1777), neto de Jorge I por descendência ilegítima, que permaneceu no país depois da declaração de paz, no ano seguinte, a pedido de Pombal, para ajudá-lo a reformar a estrutura militar portuguesa (MAXWELL, 1996, 11, 20-122).

Não sendo a preparação militar uma prioridade do Conde de Oeiras e futuro Marquês de Pombal, os ingleses reputavam como miserável o estado do exército português. Mesmo assim, devido à inconsistência e às dispersões das investidas franco-espanholas, ao apoio de tropas inglesas e à chegada a Lisboa do conde Guilherme de Schaumburg-Lippe, que era senhor de um pequeno Estado germânico e havia se tornado marechal-general e diretor de todas as armas do exército português, o reino conseguiu sobreviver à invasão, sendo assinado no final de 1762 um armistício entre os exércitos peninsulares (MONTEIRO, 2009, p. 372-373). Por outro lado, se os desdobramentos de tais conflitos denunciam a fragilidade militar de Portugal e de seus territórios, demonstrando que o exército era um reduto aristocrático difícil de ser controlado, isso não significava necessariamente que o governo não se preocupava com a formação e a organização das armas portuguesas. Em 1763, por exemplo, dando continuidade a uma série de medidas tendentes à organização dos Corpos da Milícia de Terra e Mar, D. José I decretou, no dia 10 de maio, que os Corpos de Artilharia fossem reduzidos a quatro regimentos de doze companhias cada um. Seu regulamento, expedido com o Alvará de 15 de julho, foi cometido ao "prudente exame, e madura 
consideração" do Conde Reinante de Schaumbourg Lippe, "Meu muito amado e presado primo, e Marechal General dos Meus Exércitos", segundo o soberano (apud RIBEIRO, 1871, p. 303).

Uma medida importante nesse sentido foi a Carta de Lei de 7 de março de 1761, publicando os Estatutos do Colégio Real dos Nobres - antigo Colégio das Artes dirigido pelos Jesuítas -, aberto oficialmente em 19 de março de 1766 e destinado à formação do "perfeito militar". O Plano de Estudos da nova instituição trazia novidades, pois além das matérias usuais do ensino de Humanidades (latim, grego, retórica, filosofia, teologia), estavam presentes alguns elementos das matemáticas, astronomia e física, e se achava recomendado o estudo das línguas francesa, italiana e inglesa. No Título VIII, dedicado aos seus respectivos professores, a lei repetia o discurso do pensamento pedagógico da época, ao defender a utilidade dos muitos livros escritos nas referidas línguas (PORTUGAL, 1830).

Contudo, o funcionamento da instituição, pelo menos até 1772, quando, com a reforma da Universidade de Coimbra, foi abolido o ensino das matemáticas no colégio, parece ter sido marcado pelo fracasso, sendo os professores de francês e inglês contratados somente em 1785. Entre as causas arroladas por Carvalho (1959, p. 173), estão: a deficiência da administração, o plano de estudos inadaptado à idade dos colegiais, o ensino efetuado por professores estrangeiros em língua estrangeira, a situação social dos estudantes, que, habituados às liberdades de sua classe, tinham atitudes incompatíveis com um regime de disciplina, e o desagrado dos professores, que se viam obrigados a acumular funções administrativas. O colégio foi abolido com um decreto de janeiro de 1838 .

De qualquer modo, um ano após a publicação dos estatutos foi impressa uma Grammatica ingleza ordenada em portuguez, "na qual se explicão clara, e brevemente as regras fundamentaes, e as mais proprias para falar puramente aquela lingua, composta e dedicada á magestade fidelissima de elrey Dom Jozé o I, nosso senhor", por Carlos Bernardo da Silva Teles de Menezes, militar e "fidalgo da Caza de Sua Magestade", conforme a folha de rosto do livro. A dedicatória, 
dirigida à "Vossa Magestade", creditava a El Rei os novos progressos da "Literatura Portugueza", o que justificava a temeridade do autor em dar lume à sua pequena obra, produzida, como ele mesmo afirma, nos momentos de descanso do serviço militar (MENEZES, 1762, p. iii).

A finalidade do ensino da língua inglesa, segundo Teles de Menezes, era o conhecimento dos grandes autores que nela tinham escrito suas obras "desde o principio do seculo prezente", uma vez que no século anterior aquela língua era não somente desconhecida dos estrangeiros, mas também desprezada pelos próprios naturais. Assim, ela precisava ser ensinada e aprendida para que todos pudessem fazer uso dos "excelentes originaes" nela impressos, como havia reconhecido "a Alta sabedoria de Sua Magestade Fidelíssima, quando no Tit. 8 dos Estatutos do Colégio Real dos Nobres, foy servido criar um Professor, e recomendar o estudo da dita lingua". O estímulo de sua utilidade, se era necessário a todas as "nações cultas", era-o mais ainda à portuguesa, dadas as suas relações comerciais com os ingleses, sendo indesculpável a falta de interesse dos portugueses em aprender a falar a língua de "uma gente que temos tão dentro de caza”, bem como a carência de gramáticas da língua inglesa escritas em português, ao contrário de outras línguas "que nos devem ser mais indiferentes". Conforme o autor, o mesmo não sucedia aos ingleses, que no seu idioma tinham diferentes gramáticas da língua portuguesa, em cujo estudo quase todos se iniciavam, especialmente aqueles que se aplicavam ao comércio. Nesse ponto, Teles de Menezes distingue claramente os interesses do conhecimento de cada língua nos dois países: "bem sey que os interesses deste [comércio], e não o de instruirse na lição dos nossos Autores, são o motivo daquela aplicação: mas por isso mesmo, será tanto mais louvavel em nós o estudo da sua lingua, quanto for mais nobre o motivo de aprendela" (MENEZES, 1762, p. 186). 


\section{CONCLUSÃO}

Como vimos, foi durante o governo pombalino que se institucionalizou o ensino de inglês em Portugal, seja através da instrução comercial, seja mediante a instrução militar. Assim, na história do ensino das línguas, a governação pombalina foi um divisor de águas, uma vez que, pela primeira vez, não só reformou o ensino das línguas clássicas e institucionalizou o ensino da língua materna, com a regulamentação das escolas menores, mas também o das línguas estrangeiras modernas, isto é, a então camadas "línguas vivas" (francês e inglês), que passaram a constar dos planos de estudo dos cursos recém-criados de instrução comercial e militar. Contudo, ao contrário do que certa historiografia educacional faz acreditar, não havia, propriamente, uma política pombalina de instrução pública, embora possamos falar, como Carvalho (1978), em Reformas pombalinas da instrução pública. O fato é que a conjuntura histórica e os problemas de ordem prática que o ministro de D. José teve que enfrentar forçaram-no a tomar medidas legislativas que, do ponto de vista educacional, iriam modificar fundamentalmente a estrutura estabelecida pela tradição jesuítica, o que fez com que Portugal, em muitos casos, tomasse a dianteira dos outros países da Europa nessa matéria.

Assim foi com a Lei do Diretório de 1757, que regulamentou o processo de aculturação e letramento dos indígenas e tornou o uso e o ensino da língua portuguesa obrigatório primeiramente no Brasil e depois em todos os seus domínios. Embora possa ser concebida como a primeira política linguística de um Estado europeu, surgiu em função da ruptura de Pombal com os jesuítas, "libertando", como dizia a lei, os índios de sua tutela. Assim, era parte importante de uma série de medidas confiadas ao seu irmão Francisco Xavier de Mendonça Furtado (1701-1769), Capitão General do Grão-Pará e Maranhão, com vistas a administrar a população indígena, inclusive através de uma política de mestiçagem, após a ruptura com os jesuítas, para o efetivo cumprimento do Tratado de Limites de 1750 com o reino espanhol. 
O mesmo se deu com a expulsão total dos jesuítas de Portugal e seus domínios em 1759, situação que forçou o já então Conde de Oeiras a juntar um grupo de conselheiros para preparar a reforma dos estudos de humanidades (ensino de latim, grego e retórica), dos estudos menores em 1771 e da Universidade de Coimbra em 1772. As línguas estrangeiras, de modo geral, como objeto de estudo ou de ensino, embora já houvessem sido objeto de reflexão da parte de muitos pensadores, tal como Comenius (1592-1670) e Locke (16321704), e mesmo Verney (1713-1792), vão ter o ensino institucionalizado somente com a sistematização da instrução comercial e militar, que também atendiam a necessidades prementes do reino, como fazia questão de frisar o ministro em suas correspondências e nos preâmbulos das leis.

Havia, sem dúvida, um crescente interesse pelo estudo do inglês, como sugerem os anúncios de aulas e cursos particulares publicados nos periódicos portugueses e brasileiros de fins do século XVIII e inícios do século XIX, embora o conhecimento do idioma inglês, inclusive entre as elites sociais e intelectuais, fosse bastante reduzido. Mesmo assim, como vimos, podemos afirmar que o ensino de inglês foi institucionalizado em Portugal durante o período pombalino, nos estabelecimentos dedicados à instrução militar e comercial, uma tradição que continuou no século seguinte, como mostra o caso da Academia Real de Marinha e Comércio da cidade do Porto, em 1803, da criação das cadeiras de francês e inglês no Brasil, em 1809, e os planos de estudo do Colégio Militar da Luz, fundado em 1814, que incluíam a Gramática Inglesa entre as matérias de ensino.

\section{REFERÊNCIAS}

AZEVEDO, João Lúcio de. O marquês de Pombal e a sua época. São Paulo: Alameda, 2004.

BAUMAN, Zygmunt. Legisladores e intérpretes: sobre modernidade, pósmodernidade e intelectuais. Tradução: Renato Aguiar. Rio de Janeiro: Zahar, 2010. 
CARDIM, Luís. Gramáticas inglesas para portugueses e gramáticas portuguesas para uso de ingleses. Anais das Bibliotecas e Arquivos, Lisboa, v. 3, p. 105107. Disponível em: http://purl.pt/258/1/bad-1510-v/index-geral-1HTML/M_index.html. Acesso em: 13 fev. 2012.

CARVALHO, Rómulo de. História da fundação do Colégio Real dos Nobres. Coimbra: Atlântida, 1959.

CARVALHO, Laerte Ramos de. As reformas pombalinas da instrução pública. São Paulo: Saraiva, Editora da Universidade de São Paulo, 1978.

CASTRO, Jacob. Grammatica Anglo-Lusitanica \& Lusitano-Anglica: ou, Gramatica Nova, Ingleza e Portugueza, e Portugueza e Ingleza; dividida em duas partes. A primeira para a instruição dos Inglezes que desejarem alcançar o conhecimento da Lingua Portugueza. A segunda, para o uso dos Portuguezes que tiverem a mesma inclinação a Lingua Ingleza. Das quaes a Primeira está corrigida e emendada, a segunda executada por Methodo claro, familiar, e facil. 3. ed. Londres: W. Meadows, 1759.

DARNTON, Robert. Os dentes falsos de George Washington: um guia não convencional para o século XVIII. Tradução: José Geraldo Couto. São Paulo: Companhia das Letras, 2005.

FALCON, Francisco José Calazans. A época pombalina. 2. ed. São Paulo: Ática, 1993.

GRAMSCI, Antonio. Cadernos do cárcere. Tradução: Carlos Nelson Coutinho. 4. ed. Rio de Janeiro: Civilização Brasileira, v. 2, 2006.

HOWATT, Anthony Philip Reid. A history of English language teaching. 3. ed. Oxford: Oxford University Press, 1988.

MAXWELL, Keneth. Marquês de Pombal: paradoxo do iluminismo. Tradução: Antônio de Pádua Danesi. Rio de Janeiro: Paz e Terra, 1996.

MAXWELL, Keneth. A devassa da devassa: a Inconfidência Mineira: Brasil e Portugal. Tradução de João Maia. 6. ed. São Paulo: Paz e Terra, 2005.

MELO, Sebastião José de Carvalho e. Memórias secretíssimas do Marquês de Pombal e outros escritos. Lisboa: Europa-América, 1984.

MELO, Sebastião José de Carvalho e. Escritos econômicos de Londres (1741-1742). Seleção, leitura, introdução e notas de José Barreto. Lisboa: Biblioteca Nacional [Série Pombalina], 1986. 
MENEZES, Carlos Bernardo da Silva Teles de. Gramatica ingleza ordenada em portuguez, na qual se explicão clara, e brevemente as regras fundamentaes, e as mais proprias para falar puramente aquela lingua. Lisboa: Officina Patriarcal de Francisco Luiz Ameno, 1762.

MONTEIRO, Nuno Gonçalo. Idade Moderna [séculos XV-XVIII]. In: RAMOS, Rui (coord.). História de Portugal. 5. ed. Lisboa: A Esfera dos Livros, 2009.

PORTUGAL. Collecção da Legislação Portugueza desde a ultima compilação das ordenações oferecida a El Rei Nosso Senhor pelo Desembargador Antonio Delgado da Silva. Legislação de 1802 a 1810. Lisboa: Na Typographia Maigrense, 1826.

PORTUGAL. Collecção da Legislação Portugueza desde a ultima compilação das ordenações oferecida a El Rei Nosso Senhor pelo Desembargador Antonio Delgado da Silva. Legislação de 1763 a 1774. Lisboa: Typ. de L. C. da Cunha, 1829.

PORTUGAL. Collecção da Legislação Portugueza desde a ultima das ordenações oferecida a El Rei Nosso Senhor pelo Desembargador Antonio Delgado da Silva. Legislação de 1750 a 1762. Lisboa: Typ. de L. C. da Cunha, 1830.

RIBEIRO, José Silvestre. Historia dos estabelecimentos scientificos, literarios e artisticos de Portugal nos sucessivos reinados da monarchia. Lisboa: Typographia da Academia Real das Sciencias, Tomo I, 1871.

SARAIVA, António José; LOPES, Oscar. História da literatura portuguesa. 17. ed. Porto: Porto Editora Lda., 2008.

TORRE, Manuel Gomes da. Gramáticas inglesas antigas: alguns dados para a história dos estudos ingleses em Portugal até 1820. Trabalho complementar à Dissertação de Doutoramento apresentado à Faculdade de Letras da Universidade do Porto, 1985.

TORRE, Manuel Gomes da. O interesse pelo estudo do inglês em Portugal, no séc. XVIII. In: COLÓQUIO COMEMORATIVO DO VI CENTENÁRIO DO TRATADO DE WINDSOR, Faculdade de Letras do Porto, 1986, Porto/Portugal. Actas [...]. Porto: Faculdade de Letras do Porto, 1988, p. 5-9. Disponível em: http://ler.letras.up.pt/site/default.aspx?qry=ido3id1210\&sum=sim. Acesso em: 30 jan. 2018.

TORRE, Manuel Gomes da. Who wrote A Compleat Account of the Portuguese 
Language?. Revista de Estudos Anglo-Portugueses, Lisboa, Junta Nacional de Investigação Científica e Tecnológica / Centro de Estudos Comparados de Línguas e Literaturas Modernas da Faculdade de Ciências Sociais e Humanas da Universidade Nova de Lisboa, n. 5, p. 33-47, 1996.

TWISS, Richard. Travels through Portugal and Spain, in 1772 and 1773. Londres: Printed for the Author and sold by G. Robinson, T. Becket, and J. Robson, 1775. Disponível em: http://purl.pt/17071. Acesso em: 26 dez. 2018.

LUIZ EDUARDO MENESES DE OLIVEIRA é Professor Titular do Departamento de Letras Estrangeiras e do Programa de Pós-Graduação em Educação da Universidade Federal de Sergipe (UFS). Mestre em Teoria e História Literária pela Universidade Estadual de Campinas (Unicamp - 1999) e doutor em História da Educação pela Pontifícia Universidade Católica de São Paulo (PUC-SP - 2006), com Pós-Doutorado em Literatura Comparada pela Universidade de Lisboa (2012).

E-mail: luizeduardo.dle@gmail.com

(1) http://orcid.org/0000-0002-1610-3835

Recebido em: 06 de setembro de 2019

Aprovado em: 21 de outubro de 2019

Revista História da Educação - RHE

Associação Sul-Rio-Grandense de Pesquisadores em História da Educação - Asphe

Artigo de acesso aberto distribuído nos termos de licença Creative Commons. 